\title{
Obesity, Physical Activity and Sedentary Time during Covid-19 Confinement: Moroccan Adult Study
}

\author{
EL Ghouddany Safouane ${ }^{1, *}$, Yamni Khalid ${ }^{2}$, Mouri Misk ${ }^{1}$, Aderdour Tarik ${ }^{3}$, El Arabi Fatine ${ }^{4}$, \\ Khal Layoun Soad ${ }^{1}$, Bour Abdellatif ${ }^{1}$ \\ ${ }^{1}$ Laboratory of Biology and Health (LBS), Nutrition Science Team Food and Health (ESNAS), Faculty of Sciences, \\ Ibn Tofaïl University, Morocco \\ ${ }^{2}$ Natural Sciences and Didactic Innovation Team, Regional Center for Education and Training, Rabat-Salé-Kénitra, Morocco \\ ${ }^{3}$ Laboratory of Biodiversity and Natural Resources, Faculty of Sciences, Ibn Tofail University, Kenitra, Morocco \\ ${ }^{4}$ Department of Nutrition and Dietetics, Hospital Mohammed Sekkat, Morocco
}

Received October 16, 2021; Revised December 31, 2021; Accepted January 17, 2022

\section{Cite This Paper in the following Citation Styles}

(a): [1] EL Ghouddany Safouane, Yamni Khalid, Mouri Misk, Aderdour Tarik, El Arabi Fatine, Khal Layoun Soadl, Bour Abdellatif, "Obesity, Physical Activity and Sedentary Time during Covid-19 Confinement: Moroccan Adult Study," Universal Journal of Public Health, Vol. 10, No. 1, pp. 79 - 85, 2022. DOI: 10.13189/ujph.2022.100109.

(b): EL Ghouddany Safouane, Yamni Khalid, Mouri Misk, Aderdour Tarik, El Arabi Fatine, Khal Layoun Soadl, Bour Abdellatif (2022). Obesity, Physical Activity and Sedentary Time during Covid-19 Confinement: Moroccan Adult Study. Universal Journal of Public Health, 10(1), 79 - 85. DOI: 10.13189/ujph.2022.100109.

Copyright $\odot 2022$ by authors, all rights reserved. Authors agree that this article remains permanently open access under the terms of the Creative Commons Attribution License 4.0 International License

\begin{abstract}
Introduction: The objective of this study is to study the correlation between obesity, physical activity and sedentary behavior in a sample of the population in Kénitra, Morocco. Materials and methods: The obesity assessment was based on Body Mass Index (BMI), which pertains to sedentary time and physical activity. A questionnaire was completed by participants with respect to covid-19 precautions. The level of physical activity was evaluated with the International Physical Activity Questionnaire (IPAQ) short version. Results: Our study included 100 subjects ( 50 women and 50 men), the average age was $33.83 \pm 14.72$ years. Our sample showed that 32 percent of individuals who are pre-obese and 9 percent who are obese. The IPAQ score showed that $41 \%$ of individuals had high physical activity and 37\% low physical activity and $22 \%$ moderate physical activity with an insignificant relationship between physical activity and BMI $(\mathrm{p}=0.664)$. Our study showed that $50 \%$ of individuals had sedentary activity times below 20 hours/week, and 28\% had sedentary activity times between 20 and 30 hours/week, and $18 \%$ had sedentary activity times between 30 and 40 hours/week, and $4 \%$ had a significant relationship between sedentary time and BMI $(\mathrm{p}=0.017)$. Conclusion: Our results have shown that there are inconveniences of containment on the health of individuals, requiring the intervention of specialists to find suitable solutions.
\end{abstract}

Keywords Covid-19, Inactivity, Kenitra, Morocco, Obesity, Physical Activity

\section{Introduction}

The prevalence of obesity has steadily increased worldwide, with the number of obese people reaching 700 million over the past 40 years with a high rate among adolescents and children [1,2]. Physical activity and inactivity are factors related to obesity [3]. The adoption of regular physical activity is an effective treatment for obesity and cardiovascular disease [4]. On the other hand, increased sedentary activity leads to weight gain, physical activity and sedentary behavior could be affected by the Covid-19 crisis and consequently a change in weight. In 2019 five million individuals with very high body mass index (BMI) died from Covid-19 virus [5, 6]. In Morocco as of 5 September 2021 the total number of cases has been 884,085 since the first case was identified in March 2020 [7]. With reference to WHO, physical activity is defined as any body movement produced by skeletal muscles, which leads to increased energy expenditure. Therefore, due to its close relationship with risk factors for NCDs (non-communicable diseases), regular and appropriate 
physical activity has been shown to be an essential parameter for maintaining a favorable health status [8]. The objective of this study was to correlate obesity, physical activity and sedentary behavior during the period of confinement because of Covid-19 on a sample of the population of Kenitra, Morocco.

\section{Material and Method}

\subsection{Data Collection}

This is a cross-sectional, descriptive survey of a sample of 100 individuals (50\% women (25 \pm 6$)$ and $50 \%$ men), aged 18 to 60 years, excluding pregnant women and individuals with communicable chronic diseases. The study was developed in the city of Kenitra for 2 months from the beginning of March to the end of May 2021, and was developed with many repetitions because of the covid-19 pandemic.

\subsection{Measuring Anthropometric Parameters}

The weight (in $\mathrm{Kg}$ ) was evaluated by an electronic weighting system with a precision of $0.1 \mathrm{Kg}$ on individuals stripped lightly. The size (in $\mathrm{m}$ ) was assessed using a locally manufactured toise with an accuracy of $0.5 \mathrm{~cm}$, on weathered individuals, the head oriented horizontally, feet flat, buttocks, back were placed on the vertical board of the aircraft. The BMI (body mass index) was used as a rule to assess the weight status of respondents by weight-to-squared height BMI=Weight $/ \mathrm{Size}^{2}\left(\mathrm{~kg} / \mathrm{m}^{2}\right)$ and was considered a reliable index by WHO.

\subsection{Measurement of Inactivity}

Sedentarily was measured by the time spent sitting during the last seven days of the week and this includes time spent sitting at home (computer, television, video games, reading) and away from home (cafeteria, restaurant, work, company canteen). The average time was estimated in minutes per Seven Days and the values obtained were classified into Four classes: less than 20 hours per week (< 20 hours/7 days), between 20 and 30 hours per week (20-30 hours/7 days), between 30 and 40 hours per week (30-40 hours/7 days), more than 40 hours per week ( $>40$ hours/7 days).

\subsection{Measuring Physical Activity}

The measurement of sedentarity was based on the International Physical Activity Questionnaire (IPAQ) in its short version [9]. The questionnaire enabled us to evaluate Physical activity based on intensity (high, moderate, walking) over the last seven days, by duration intensity frequency IPAQ group cited a rule that allows energy expenditure to be evaluated for one week in metabolic equivalents (MET) in its MET-minutes/week unit and thanks to this evaluation the population has subdivided into three categories (high, moderate and low) [10].

\subsection{Statistical Analysis}

The data were entered and processed by Statistical Package for Social Science (SPSS) Version 17.5. And Statistical Analysis System (SAS) Version 9.3. The results obtained are expressed as percentage or mean \pm standard deviation. The Pearson test was used to test the correlation between BMI and physical activity and between BMI and sedentary behavior. The value $\mathrm{p}<0.05$ represents the significance threshold for the tests performed.

\section{Results}

\subsection{Evaluation of Anthropometric Parameters}

A total of 100 participants (50 women and 50 men) were selected. Their average age was $33.83 \pm 14.72$ years, the average weight was $71.11 \pm 13.28 \mathrm{Kg}$, the average height was $168.65 \pm 9.35 \mathrm{~m}$, and the average BMI was $24.86 \pm 4.35$ $\mathrm{Kg} / \mathrm{m}^{2}$, the results as shown in Table 1 .

Table 1. Means of anthropometric characteristics of the entire population and in both sexes

\begin{tabular}{|c|c|c|c|}
\hline & $\begin{array}{c}\text { Female (average/Et) } \\
\mathbf{N = 5 0}\end{array}$ & $\begin{array}{c}\text { Men (average/Et) } \\
\mathbf{N = 5 0}\end{array}$ & $\begin{array}{c}\text { Female + men (average/Et) } \\
\mathbf{N = 1 0 0}\end{array}$ \\
\hline Age (years) & $29,90 \pm 0,00$ & $37,76 \pm 0,00$ & $33,83 \pm 14,72$ \\
\hline Weight $(\mathbf{K g})$ & $63,72 \pm 10,40$ & $78,51 \pm 11,69$ & $71,11 \pm 13,28$ \\
\hline Height $(\mathbf{c m})$ & $162,65 \pm 0,00$ & $174,66 \pm 0,00$ & $168,65 \pm 9,35$ \\
\hline BMI $\left(\mathbf{k g} / \mathbf{m}^{\mathbf{2}}\right)$ & $23,96 \pm 0,00$ & $25,77 \pm 0,00$ & $24,86 \pm 4,35$ \\
\hline
\end{tabular}




\subsection{Evaluation of Physical Activity and Sedentary Time during Confinement}

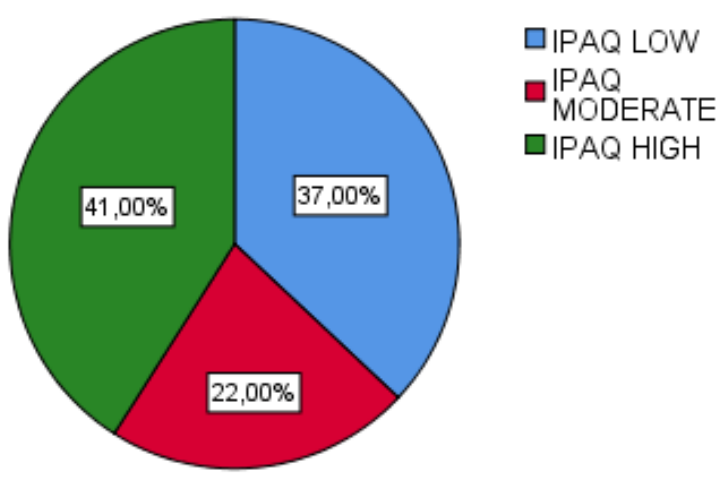

Figure 1. A circular histogram shows the percentage of the three levels of physical activity

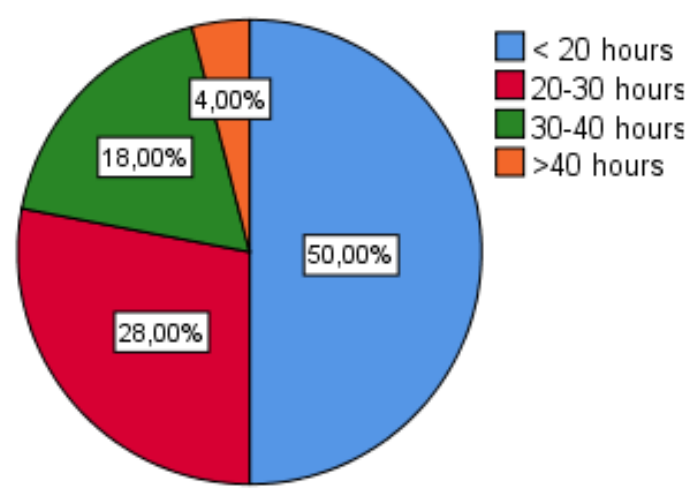

Figure 2. Circular histogram shows the percentage of sedentary time in hour intervals for seven days
Figure 1 presents a circular histogram of the percentage of the three levels of physical activity adopted by individuals in our population, based on the short version of the International Physical Activity Questionnaire (IPAQ). Results showed that $41 \%$ of individuals have high physical activity and $37 \%$ have low physical activity and $22 \%$ of individuals have moderate physical activity.

Figure 2 shows a circular histogram of the percentage of sedentary time in hour intervals for seven days. The results show that $50 \%$ of the individuals have a sedentary activity time of less than 20 hours/week, and $28 \%$ between 20 and 30 hours/week, and $18 \%$ between 30 and 40 hours/week, as well as $4 \%$ exceeds 40 hours/week.

\subsection{The Relationship between Overweight and Physical Activity}

The results showed that in subjects with high PA, their maximum BMI average of $36.94 \pm 0.00$ (morbid obesity) and the minimum BMI average of $11.19 \pm 0.00$ (meanness), and in subjects with moderate and low PA, the maximum BMI average was $31.13 \pm 1.10$ (obese) and $36.94 \pm 0.00$ (morbid obesity), respectively. The Pearson test also showed a non-significant relationship between physical activity level and overweight $(\mathrm{p}=0.664)$. Our results also showed that the maximum BMI average of $32.02 \pm 0.66$ (Obese) was observed in subjects with a sedentary time of less than 20 hours/week, and the Pearson test showed a significant relationship between overweight and sedentary time $(\mathrm{p}=0.017)$. The results of measuring the PA and the sedentary time of our participants by weight status are shown in Table 2.

Table 2. Association of obesity with physical activity and sedentary time

\begin{tabular}{|c|c|c|c|c|c|c|c|}
\hline & & \multicolumn{5}{|c|}{ Body Mass Index (BMI) } & \multirow{2}{*}{$\begin{array}{c}\text { Pearson } \\
\text { test }\end{array}$} \\
\hline & & $\begin{array}{c}\mathbf{M} \\
\text { (average/Et) }\end{array}$ & $\begin{array}{c}\mathbf{C N} \\
\text { (average/Et) }\end{array}$ & $\begin{array}{c}\text { SO } \\
\text { (average/Et) }\end{array}$ & $\begin{array}{c}\mathbf{O} \\
\text { (average/Et) }\end{array}$ & $\begin{array}{c}\mathbf{O M} \\
\text { (average/Et) }\end{array}$ & \\
\hline \multirow{3}{*}{$\begin{array}{c}\text { Level of physical } \\
\text { activity }\end{array}$} & Low & $0,00 \pm 0,00$ & $22,51 \pm 1,77$ & $27,70 \pm 1,06$ & $33,06 \pm 1,04$ & $36,94 \pm 0,00$ & \multirow{3}{*}{$\mathrm{p}=0,664 * *$} \\
\hline & moderate & $17,13 \pm 1,07$ & $21,51 \pm 1,48$ & $26,36 \pm 1,47$ & $31,13 \pm 1,10$ & $0,00 \pm 0,00$ & \\
\hline & high & $11,19 \pm 0,00$ & $22,25 \pm 1,88$ & $26,87 \pm 1,10$ & $31,80 \pm 0,80$ & $35,88 \pm 0,00$ & \\
\hline \multirow{4}{*}{$\begin{array}{l}\text { Sedentary time } \\
\text { (hour/week) }\end{array}$} & $<20$ & $14,78 \pm 5,08$ & $22,08 \pm 1,81$ & $26,66 \pm 1,30$ & $32,02 \pm 0,66$ & $0,00 \pm 0,00$ & \multirow{4}{*}{$\mathrm{p}=0,017^{*}$} \\
\hline & $20-30$ & $16,51 \pm 0,03$ & $22,64 \pm 1,72$ & $26,70 \pm 1,16$ & $30,85 \pm 0,57$ & $0,00 \pm 0,00$ & \\
\hline & $30-40$ & $0,00 \pm 0,00$ & $22,80 \pm 1,61$ & $27,83 \pm 1,22$ & $31,91 \pm 2,67$ & $36,94 \pm 0,00$ & \\
\hline & $>40$ & $0,00 \pm 0,00$ & $21,27 \pm 3,01$ & $26,62 \pm 0,00$ & $0,00 \pm 0,00$ & $35,88 \pm 0,00$ & \\
\hline
\end{tabular}

**Significant difference $* *$ no significant difference.

M: thin, CN: Normal Corpulence, SO: Overweight/near-obese, O: Obese, OM: Morbid Obesity 


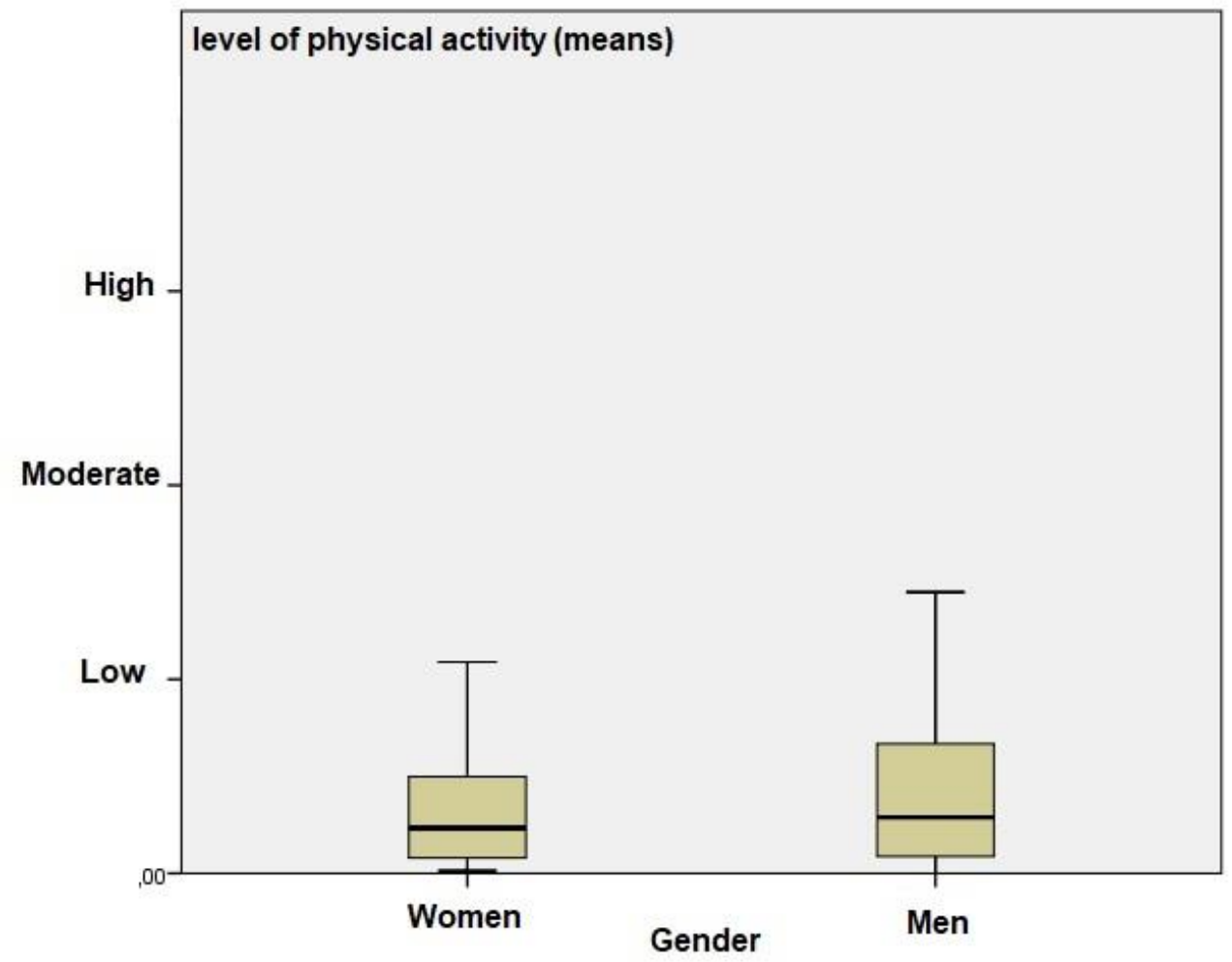

Figure 3. Boxplot representing the relationship between the level of physical activity and gender

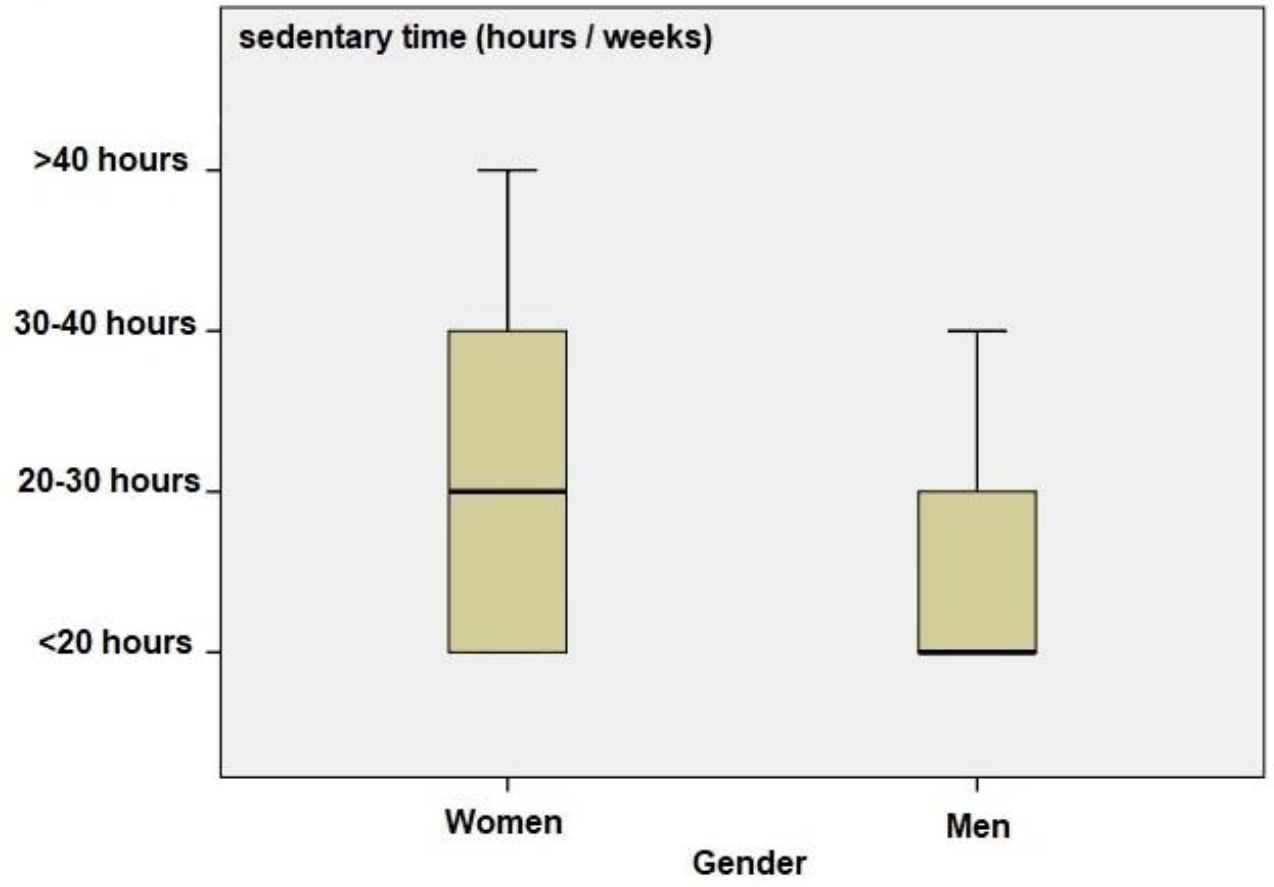

Figure 4. Boxplot representing the relationship sedentary time and gender

To confirm the results found we carry out the boxplot test to confirm the results found, and according to figures 3 and 4 our results are logical and correct.

\section{Discussion}

The frequency of obesity in our population defined according to the WHO criteria during the period of 
confinement due to Covid-19 was $32 \%$ of the individuals who are pre-obese and 9\% who are obese with the predominance of men $(72.7 \%)$ than women $(27.3 \%)$. These BMI values are comparable with another study that was conducted on a population of 2002 British adults during the period of confinement due to covid-19, the study found that $32 \%$ of the sample were classified as obese [11].

Several studies suggest that sedentary behavior, or lack of physical activity, has been among the determinants of obesity and cardiovascular disease $[12,13,14]$. In our case the weight overload was higher in subjects who spent more than 30 hours/week sitting and we also found that the increase in sedentary time was significantly associated with the increase in BMI (Body Mass Index). This result is consistent with a study in Tunisia which showed that the prevalence of obesity has been higher among people who have passed 28 hours per week [15]. This result could be explained by the increase in energy intake due to the increase in seated time that excites the appetite and as a result increased consumption of food during the containment period as pointed out by C. Ebbeling et al [16] by a study of children and which found that subjects consumed a higher amount of food in time sitting in front of the television. Precautionary measures during containment with a negative effect on the behaviors of weight gain protection as shown by Rebecca L. Pearl in 2020 [17], who suggested that restrictions to limit the spread of Covid-19 led to a rise in prominence among the population.

In the same vein, studies have shown that the adoption of a low sedentary time leads to a decrease in the value of the BMI $[18,19]$.

In our study the level of physical activity of our participants, according to the IPAQ score, was low in $37 \%$ of cases, moderate in $22 \%$ of cases, and high in $41 \%$ of cases. As respondents stated, they encountered barriers that affected physical activity. Our results are different from another study conducted in the city of Kenitra using a General Physical Activity Questionnaire (GPAQ) which found that $58.4 \%$ of adults have low levels of physical activity, 23.2\% have moderate levels of physical activity, and $17.5 \%$ have shown high levels of physical activity (according to the GPAQ Analysis Guide) [20]. Several studies suggest that there is a significant relationship between physical activity and obesity [21, 22]. According to our results, no significant difference has been observed between physical activity and the Weighting of individuals, our result and in agreement with several studies [23, 24]. Probably there are other factors accompanying containment that could influence weight gain, e.g. psychic factor (depression and negative emotion) or eating behavior [25, 26], this factor could cause hyperphagic access and thus weight gain [27]. Those affected by this eating behavior disorder are most at risk of attack by Covid-19 (obesity is affecting cellular immunity) as well as the availability and accessibility of food (storage) during containment would trigger food stimulus and as a result increase in weight gain, these factors may explain results obtained during containment due to Covid-19 [28, 29, 30].

In order to test these assumptions, further studies will come to understand the mechanisms involved in the risk of eating disorder relapse in this specific context such as a study carried out in Canada which found that a plant-based diet can reduce weight [31]. This will allow the care of patients with eating disorder to be adapted to the best possible extent and prevent the onset of eating disorder, by providing a case-by-case care according to the mechanisms specifically involved for a given individual.

\section{Conclusions}

Our results show that containment related to Covid-19 has an impact on weight-status in adults in the city of Kenitra. Indeed, people with high sedentary rates are likely to be obese, which requires an adequate strategy to combat weight gain during and after the confinement period and to encourage physical activity and to raise awareness among patients about diet and the adverse effects of sedentary behavior, all of which will protect individuals' health from obesity-related diseases. Further work is needed to reveal the consequences of containment for public health.

\section{REFERENCES}

[1] NCD Risk Factor Collaboration (NCD-RisC)., "Worldwide trends in body-mass index, underweight, overweight, and obesity from 1975 to 2016: a pooled analysis of 2416 population-based measurement studies in 128_9 million children, adolescents, and adults," THE LANCET, vol. 390, no. 10113, pp. 2627-2642, 2017. DOI: 10.1016/S0140 $-6736(17) 32129-3$.

[2] NCD Risk Factor Collaboration (NCD-RisC)., "Heterogeneous contributions of change in population distribution of body mass index to change in obesity and Underweight," Elife, vol. 3, no. 9, 2021. DOI: https://doi.o $\mathrm{rg} / 10.7554 /$ eLife.60060.

[3] C Ciangura., P Faucher., JM Oppert., "Activité physique, nutrition et obésité (Physical activity, nutrition and obesity)," Nutrition Clinique et Métabolisme, vol. 28, no. 4, pp. 279-286, 2014. DOI:https://doi.org/10.1016/j.nupar.20 14.08.001.

[4] French S A., Story M., Jeffery R W., "Environmental influences on eating and physical activity," Annual Review of Public Health, vol. 22, no. May, pp. 309-335, 2001.DOI:https://doi.org/10.1146/annurev.publhealth.22.1 .309 .

[5] Oppert JM.,"activité physique, sédentarité et gain de poids," SCIENCES DES ALIMENTS, vol. 24, no. 2, pp. 115-120, 2004. DOI: doi:10.3166/sda.24.115-120.

[6] GBD 2019 Risk Factors Collaborators., "Global burden of 
87 risk factors in 204 countries and territories, 1990_2019: a systematic analysis for the global burden of disease study 2019," THE LANCET, vol. 396, no. 10258, pp. 1223-1249, 2020. DOI: https://doi.org/10.1016/S0140-673 6(20)30752-2.

[7] AY., "Maroc," LesEco, https://www.leseco.ma (Accessed on September.5, 2021).

[8] El Haboussi A., Hilali MK., Loukid M., "Evaluation de l'activité physique et son association avec l'embonpoint (obésité incluse) chez des adolescents scolarisés dans la ville de Marrakech et la province d'Al-Haouz au Maroc," Antropo, vol. 37, pp. 37-47, 2017. http://www.didac.ehu.es /antropo

[9] The IPAQ group., "Guidelines for the data processing and analysis of the International Physical Activity Questionnaire (IPAQ) Short and Long Forms," International Physical Activity Questionnaire (IPAQ). http s://sites.google.com/site/theipaq (Accessed on January. 19, 2015).

[10] Craig CL., Marshall AL., Sjostrom M., Bauman AE., Booth ML., Ainsworth BE., Pratt M., Ekelund U., Yngve A., Sallis JF., "Oja P? International physical activity questionnaire: 12-country reliability and validity," Med Sci Sports Exerc, vol. 35, no. 8, pp. 1381-1395, 2003. DOI: 10.1249/01.MSS.0000078924.61453.FB.

[11] Robinson E., Boyland E., Chisholm A., et al, "Obesity, eating behavior and physical activity during COVID-19 lockdown: a study of UK adults," Appetite, vol. 156, 104973, 2021. DOI: https://doi.org/10.1016/j.appet.2020.1 04853.

[12] Word Health Organization., "Global strategy on diet, physical activity and health: childhood overweight and obesity," http://www.who.int/dietphysicalactivity/childhoo d/en/(accessed Dec 21, 2015).

[13] Tremblay MS., LeBlanc AG., Kho ME., Saunders TJ., Larouche R., Colley RC., Goldfield G., Connor Gorber S, "Systematic review of sedentary behaviour and health indicators in school-aged children and youth," International Journal of Behavioral Nutrition and Physical Activity, vol. 8, no. 98, 2011. DOI: https://doi.org/10.1186/1479-5868-8-98.

[14] World Health Organization., "Global status report on noncommunicable diseases 2010," http://www.who.int/nm h/publications/ncd_report_full_en.pdf. (Accessed on January.19, 2015).

[15] Regaieg S., Charfi N., Elleuch M., et al., "Obésité, activité physique et temps de sédentarité chez des adolescents scolarisés, agés de 15 à 18 ans de la ville de Sfax (Tunisie)," Pan African Medical Journal, vol. 22, no. 1, 2015.

DOI:https://doi.org/10.11604/pamj.2015.22.370.6121.

[16] Ebbeling CB., Pawlak DB., Ludwig DS., "Childhood obesity: Public health crisis, common sense cure". Lancet, vol. 360, no. 9331, pp. 473-482, 2002. DOI: https://doi.org/10.1016/S0140-6736(02)09678-2.

[17] Rebecca L. Pearl., "Weight stigma and the "quarantine-15," Obesity (Silver Spring), vol. 28, no. 7, pp. 1180-1181, 2020. DOI: https://doi.org/10.1002/oby.22850.
[18] Liao Y1., Liao J., Durand CP., Dunton GF., "Which type of sedentary behaviour intervention is more effective at reducing body mass index in children ? A meta-analytic review," Obesity Reviews, vol. 15, no. 3, pp. 159-168, 2014. DOI: https://doi.org/10.1111/obr.12112.

[19] Robinson T N., "Reducing children's television viewing to prevent obesity: a randomized controlled trial," JAMA, vol. 282, no. 16, pp. 1561- 1567, 1999. DOI: 10.1001/jama.282.16.1561.

[20] Zeghari L., Aboussaleh Y., Ateilah K., Bour A., "Physical Activity and Sedentary Behavior among Diabetic from the Provincial Referral Center of Diabetes, Kenitra, Morocco," Adv Obes Weight Manag Control, vol. 8, no. 1, 00221, 2018. DOI: 10.15406/aowmc.2018.08.00221.

[21] Dumoulin C., Reynes E., Berthouze S., "Modification durable des habitudes de vie par l'activité physique dans la lutte contre l'obésité chez l'adulte: présentation du protocole de faisabilité," Obésité, vol. 12, no. 4, PP. 291 296, 2017. https://doi.org/10.1007/s11690-017-0588-3.

[22] "Position de consensus: activité physique et obésité chez l'enfant et chez l'adultePosition statement: Physical activity and obesity in adults and in children", Science et sports, vol. 25, no. 4, pp. 207-225, 2010. DOI: https://doi.org/10.1016/j.scispo.2010.04.001.

[23] Allam O., Oulamara H., Agli AN., "Prévalence et facteurs de risque du surpoids chez des enfants scolarisés dans une ville de l'est algérien (Constantine) [Prevalence and risk factors of overweight in schoolchildren in a city in eastern Algeria (Constantine)]," Antropo, vol. 35, pp. 91-102, 2016. http://www.didac.ehu.es/antropo

[24] Yousif MM., Kaddam LA., Humeda HS., "Correlation between physical activity, eating behavior and obesity among Sudanese medical students Sudan," BMC Nutrition, vol. 5, no. 6, 2019. DOI: https://doi.org/10.1186/s40795-01 9-0271-1.

[25] Brooks SK., Webster RK., Smith LE., et al., "The psychological impact of quarantine and how to reduce it: rapid review of the evidence," THE LANCET, vol. 39 5, no.

10227, pp. 912-920, 2020. DOI: https://doi.org/10.1016/S0 $140-6736(20) 30460-8$.

[26] El Ghouddany S., Yamni k., Bour A., Khal Layoun S., "The Impact of Eating Behavior on Obesity in Northwestern Morocco: Kenitra Region," Universal Journal of Public Health, Vol. 9, No. 5, pp. 344 - 351, 2021. DOI: $10.13189 /$ ujph.2021.090518.

[27] Stice E., "Risk and maintenance factors for eating pathology: a meta-analytic review," Psychological Bulletin, vol. 128, no. 5, pp 825-848, 2002. DOI: $10.1037 / / 0033-2909.128 .5 .825$.

[28] Nova E., Samartín S., Gómez S., et al., "The adaptive response of the immunesystem to the particular malnutrition of eating disorders," European Journal of Clinical Nutrition, vol. 56, no. 3, pp. 34-37, 2002. DOI: $10.1038=$ sj.ejen .1601482 .

[29] Simonnet A., Chetboun M., Poissy J., et al., "High prevalence of obe-sity in severe acute respiratory syndrome coronavirus-2 (SARS-CoV-2) requiring invasive 
mechanical ventilation," Obesity (Silver Spring), vol. 28 , no. 7, pp. 1195-1199, 2020. DOI: http://dx.doi.org/10.1002 loby.22831.

[30] Wolz I., Fagundo AB., Treasure J., et al., "The processing of food stimuli in abnor-mal eating: a systematic review of electrophysiology," European Eating Disorders Review, vol. 23, no. 4, pp. 251-261, 2015. DOI: https://doi.org/10.1 002/erv.2366.

[31] Prosper M. Bernard, "Health Management Model: A Case Study for Success," Universal Journal of Public Health, Vol. 9, No. 2, pp. 51 - 56, 2021. DOI: 10.13189/ujph.2021.090203 